\title{
One-year clinical and angiographic results of hybrid myocardial revascularization: Still a long way to go
}

\author{
Carlos A. Mestres, MD, PhD, FETCS
}

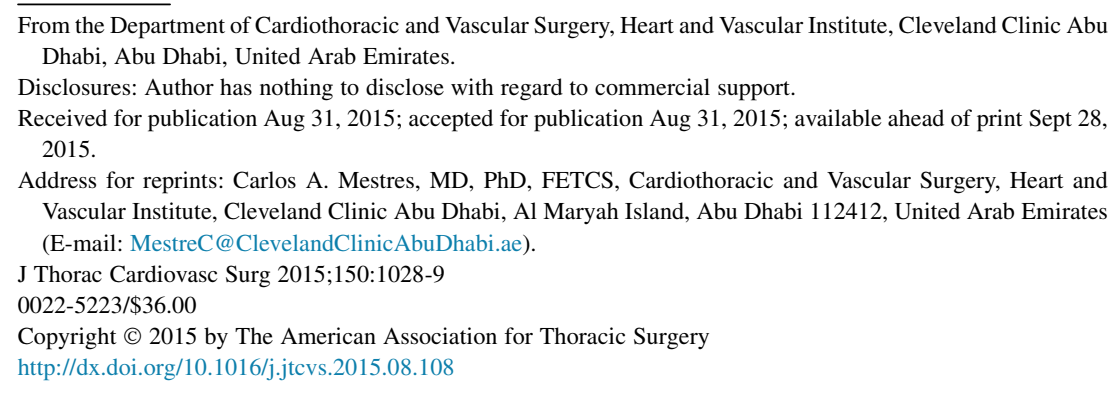

Coronary artery bypass grafting (CABG) is the mainstay of the surgical treatment of multivessel coronary artery disease. In the past 50 years, CABG has been analyzed through countless contributions, including randomized trials and observational single-institution studies. When attempting to define the key component of success of CABG, it is likely that the use of the left internal thoracic artery (LITA) to revascularize the left anterior descending coronary artery (LAD) under cardioplegic arrest will be acknowledged by a significant proportion of the medical and surgical community. This was highlighted by Loop and colleagues ${ }^{1}$ from the Cleveland Clinic in a seminal contribution. Loop ${ }^{2}$ defined the major factors that have influenced the indications for surgery in patients with left ventricular dysfunction as viable or nonviable myocardium, improved myocardial protection and intra-aortic balloon pumping, internal thoracic artery grafting, and left ventricular restorative procedures. Furthermore, current knowledge indicates that the use of a second arterial graft, mostly the right internal thoracic artery, adds long-term survival benefit in addition to higher patency with respect vein grafts, ${ }^{3}$ such as complete arterial revascularization might also offer. ${ }^{4,5}$ On top of this, the Synergy Between Percutaneous Coronary Intervention With TAXUS and Cardiac Surgery (SYNTAX) trial confirmed that surgery has superior outcomes relative to other interventions for multivessel coronary artery disease. ${ }^{6}$

In this issue of the Journal, Modrau and colleagues ${ }^{7}$ report 1-year clinical and angiographic results of hybrid coronary revascularization (HCR) after combined offpump LITA grafting through an inferior hemisternotomy with percutaneous coronary intervention (PCI) in 100 consecutive patients. The primary end point of major adverse cardiac and cerebrovascular event rate at 1 year was reached by $20 \%$. Sixteen patients underwent repeated revascularization, with 5 surgical reinterventions occurring during the index hospitalization. After discharge, PCI was performed in 8 patients. At 1 year, the LITA patency was $98 \%$. The main message from Modrau and colleagues ${ }^{7}$ is

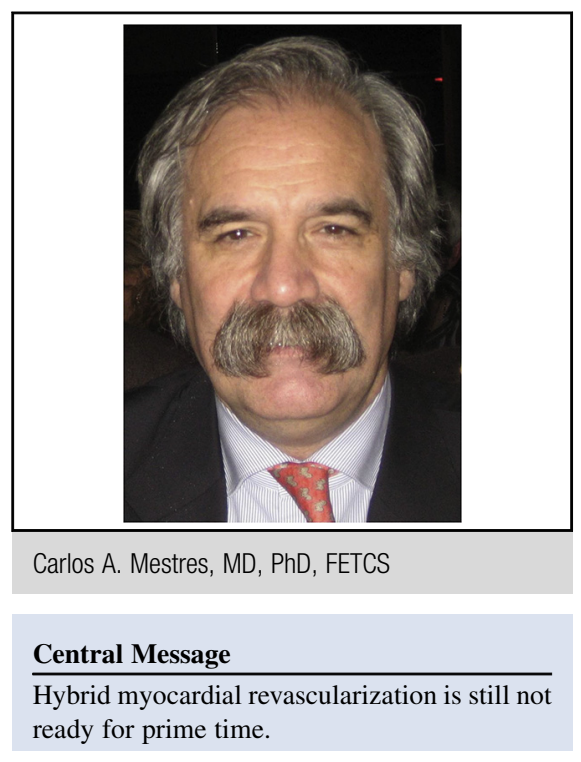

See Article page 1181 . that the association of high LITA patency with low risk of death and stroke seems to make this strategy promising for long-term outcomes, with the understanding that nonLAD lesion revascularization remains a major challenge.

This interesting single-center feasibility study confirms a 98\% LITA patency for patients with in-hospital reinterventions, which allows Modrau and colleagues ${ }^{7}$ to stress the survival benefits of the LITA-LAD association. Modrau and colleagues $^{7}$ chose to use an off-pump with inferior hemisternotomy approach to reduce invasiveness and risk of stroke. HCR has been addressed in the past, but this contribution has the added value of producing substantial angiographic information, although just out to 1 year. Selection criteria were well defined, and surgery with PCI was scheduled in different sequences according to the status of the non-LAD lesions.

Two areas are of major concern for Modrau and colleagues $^{7}$ and for the readership. First, the 20\% major adverse cardiac and cerebrovascular event rate is acknowledged to be unexpectedly high and not in line with the 1and 5-year SYNTAX data, 6,8 although an argument may be raised as to whether repeated revascularization was the major driver of this discrepancy. In-hospital and postdischarge repeated revascularization accounted for as many as $16 \%$ of the events within 1 year. Second, in-hospital revascularization was higher than the rate of repeated revascularization after conventional CABG of less than $1 \%$ reported by the same authors at the same institution. 
Another topic for discussion is stroke. Modrau and colleagues ${ }^{7}$ are concerned about stroke rates at 1 year after CABG relative to rates after PCI. This feasibility study is still limited to this short period of observation, however, and the 5-year data from the SYNTAX trial confirmed no difference in stroke between CABG and PCI, regardless of whatever the real underlying mechanism would turn out to be. ${ }^{6}$ Finally, Modrau and colleagues ${ }^{7}$ managed a highly selected population. The results from their own conventional CABG practice seem to be optimal as well, and therefore that could be taken by the readership as an intriguing question as to why the change in the departmental strategy.

The conclusions drafted by Modrau and colleagues, ${ }^{7}$ that their reported high out-of-hospital LITA patency and low risk of death and stroke seem promising for the long-term outcome of HCR, need to be carefully dissected. Current data from conventional revascularization are strong enough that it need not be challenged for the time being. First, as stated by Drinkwater in his elegant analysis of recently published purely surgical data from the SYNTAX 5-year followup ${ }^{10}$ there was no survival advantage at 5 years in multiple arterial grafting; this may collide with the results of large institutional studies. ${ }^{3-5}$ But this finding, of course, stresses once again the absolute role of the LITA-LAD association as the major driver for late success of conventional CABG, as agreed by everybody, with on-pump strategy lying beneath, as suggested by another Danish contribution in the form of randomized study supporting previous information. ${ }^{11}$ The conclusion that non-LAD lesion revascularization remains a challenge needs to be appraised in a careful way. With the understanding that the HCR aims at incorporating the best of both worlds, available information as of today clearly supports the consistent role of an on-pump strategy in yielding complete revascularization. The Danish On-pump versus Off-pump Randomization Study DOORS study ${ }^{11}$ and a meta-analysis of a number of contributions including in excess of 100,000 patients $^{12}$ are clear in this regard. These seem to be good pieces of scientific methodology. The objective words of Sabik ${ }^{13}$ highlight the wellknown fact that the effectiveness of CABG is related directly to graft patency and to completeness of revascularization.

There still remain some points to discuss from the contribution of Modrau and colleagues. ${ }^{7}$ Terminology might need to be adjusted, because what they actually refer to are, according to their description, staged procedures rather than truly hybrid procedures. Although there is some international trending toward use of the term "coronary revascularization," this should be definitively phrased as "myocardial revascularization," as used in guidelines. ${ }^{14}$ Different combinations with respect to the performance of LITA -LAD and PCI need to be clearly defined for the community, because we may not understand what has to be done first or last. Strategies for intraoperative prevention of stroke as epiaortic ultrasound have to be considered. ${ }^{15}$ Finally, the issue of unbiased information on long-term outcomes to be given to the patient is a key point in the decision.

Modrau and colleagues ${ }^{7}$ should be commended for collecting angiographic data at 1 year after discharge, but available literature indicates that staged procedures need to be assessed at least beyond 5 years, because the followup discussed in this article is simply not long enough to be compared with CABG outcomes.

\section{References}

1. Loop FD, Lytle BW, Cosgrove DM, Stewart RW, Goormastic M, Williams GW, et al. Influence of the internal-mammary-artery graft on 10-year survival and other cardiac events. N Engl J Med. 1986;314:1-6.

2. Loop FD. Coronary artery surgery: the end of the beginning. Eur J Cardiothorac Surg. 1998; 14:554-71.

3. Lytle BW, Blackstone EH, Loop FD, Houghtaling PL, Arnold JH, Akhrass R, et al. Two internal thoracic artery grafts are better than one. J Thorac Cardiovasc Surg. 1999;117:855-72.

4. Buxton BF, Shi WY, Tatoulis J, Fuller JA, Rosalion A, Hayward PA. Total arterial revascularization with internal thoracic and radial artery grafts in triple-vessel coronary artery disease is associated with improved survival. $J$ Thorac Cardiovasc Surg. 2014;148:1238-43; discussion 1243-4.

5. Locker C, Schaff HV, Dearani JA, Joyce LD, Park SJ, Burkhart HM, et al. Multiple arterial grafts improve late survival of patients undergoing coronary artery bypass graft surgery: analysis of 8622 patients with multivessel disease. Circulation. 2012;126:1023-30.

6. Head SJ, Davierwala PM, Serruys PW, Redwood SR, Colombo A, Mack MJ et al. Coronary artery bypass grafting vs. percutaneous coronary intervention for patients with three-vessel disease: final five-year follow-up of the SYNTAX trial. Eur Heart J. 2014;35:2821-30.

7. Modrau IS, Holm NR, Mæng M, Bøtker HE, Christiansen EH, Kristensen S, et al. Hybrid Coronary Revascularization Study Group. One-year clinical and angiographic results of hybrid coronary revascularization. J Thorac Cardiovasc Surg. 2015;150:1181-6.

8. Serruys PW, Morice MC, Kappetein AP, Colombo A, Holmes DR, Mack MJ, et al. Percutaneous coronary intervention versus coronary-artery bypass grafting for severe coronary artery disease. $N$ Engl J Med. 2009;360:961-72. Erratum in: N Engl J Med. 2013;368:584.

9. Drinkwater DC Jr. Multiple arterial grafting: stay the course. J Thorac Cardiovasc Surg. 2015;150:452-3.

10. Parasca CA, Head SJ, Mohr FW, Mack MJ, Morice MC, Holmes DR Jr, et al; SYNTAX Investigators. The impact of a second arterial graft on 5-year outcomes after coronary artery bypass grafting in the Synergy Between Percutaneous Coronary Intervention With TAXUS and Cardiac Surgery Trial and Registry J Thorac Cardiovasc Surg. 2015;150:597-606.e2.

11. Houlind K, Fenger-Grøn M, Holme SJ, Kjeldsen BJ, Madsen SN, Rasmussen BS et al; DOORS Study Group. Graft patency after off-pump coronary artery bypass surgery is inferior even with identical heparinization protocols: results from the Danish On-pump Versus Off-pump Randomization Study (DOORS). J Thorac Cardiovasc Surg. 2014;148:1812-9.e2.

12. Takagi H, Umemoto $\mathrm{T}$; All-Literature Investigation of Cardiovascular Evidence (ALICE) Group. Worse long-term survival after off-pump than onpump coronary artery bypass grafting. J Thorac Cardiovasc Surg. 2014;148: 1820-9.

13. Sabik JF III. On-pump coronary revascularization should be our preferred surgical revascularization strategy. J Thorac Cardiovasc Surg. 2014;148:2472-4.

14. Kolh P, Windecker S, Alfonso F, Collet JP, Cremer J, Falk V, et al; Task Force on Myocardial Revascularization of the European Society of Cardiology and the European Association for Cardio-Thoracic Surgery; European Association of Percutaneous Cardiovascular Interventions. 2014 ESC/EACTS guidelines on myocardial revascularization: the Task Force on Myocardial Revascularization of the European Society of Cardiology (ESC) and the European Association for Cardio-Thoracic Surgery (EACTS). Developed with the special contribution of the European Association of Percutaneous Cardiovascular Interventions (EAPCI). Eur J Cardiothorac Surg. 2014;46:517-92.

15. Joo HC, Youn YN, Kwak YL, Yi GJ, Yoo KJ. Intraoperative epiaortic scanning for preventing early stroke after off-pump coronary artery bypass. Br J Anaesth 2013;111:374-81. 